\title{
Hematopoietic Stem Cell Transplantation Resolves the Immune Deficit Associated with STAT3-Dominant-Negative Hyper-lgE Syndrome
}

\author{
Stephanie C. Harrison ${ }^{1} \cdot$ Christo Tsilifis ${ }^{1,2} \cdot$ Mary A. Slatter $^{1,2} \cdot$ Zohreh Nademi $^{2} \cdot$ Austen Worth $^{3} \cdot$ Paul Veys $^{3} \cdot$ \\ Mark J. Ponsford ${ }^{4,5}$. Stephen Jolles ${ }^{4} \cdot$ Waleed Al-Herz $^{6} \cdot$ Terence Flood $^{2} \cdot$ Andrew J. Cant $^{1,2} \cdot$ Rainer Doffinger $^{7}$. \\ Gabriela Barcenas-Morales ${ }^{8}$. Ben Carpenter ${ }^{9} \cdot$ Rachael Hough $^{9} \cdot$ Ásgeir Haraldsson ${ }^{10}$. Jennifer Heimall ${ }^{11}$. \\ Bodo Grimbacher $^{12}$. Mario Abinun ${ }^{1,2}$. Andrew R. Gennery ${ }^{1,2}$ (D)
}

Received: 21 May 2018 / Accepted: 13 January 2021 / Published online: 1 February 2021

(C) The Author(s) 2021

\begin{abstract}
Autosomal dominant hyper-IgE syndrome caused by dominant-negative loss-of-function mutations in signal transducer and activator of transcription factor 3 (STAT3) (STAT3-HIES) is a rare primary immunodeficiency with multisystem pathology. The quality of life in patients with STAT3-HIES is determined by not only the progressive, life-limiting pulmonary disease, but also significant skin disease including recurrent infections and abscesses requiring surgery. Our early report indicated that hematopoietic stem cell transplantation might not be effective in patients with STAT3-HIES, although a few subsequent reports have reported successful outcomes. We update on progress of our patient now with over 18 years of follow-up and report on an additional seven cases, all of whom have survived despite demonstrating significant disease-related pathology prior to transplant. We conclude that effective cure of the immunological aspects of the disease and stabilization of even severe lung involvement may be achieved by allogeneic hematopoietic stem cell transplantation. Recurrent skin infections and abscesses may be abolished. Donor $\mathrm{T}_{\mathrm{H}} 17$ cells may produce comparable levels of IL17A to healthy controls. The future challenge will be to determine which patients should best be offered this treatment and at what point in their disease history.
\end{abstract}

Keywords Autosomal dominant hyper IgE syndrome $\cdot$ dominant-negative STAT3 mutations $\cdot$ hematopoietic stem cell transplantation $\cdot$ Job syndrome $\cdot$ STAT3-HIES T $\mathrm{H}_{\mathrm{H}} 17$ cells

Andrew R. Gennery

a.r.gennery@ncl.ac.uk

1 Translational and Clinical Research Institute, Newcastle University, Newcastle upon Tyne, UK

2 Paediatric Haematopoietic Stem Cell Transplant Unit, Great North Children's Hospital, Clinical Resource Building, Floor 4, Block 2, Queen Victoria Road, Newcastle upon Tyne NE1 4LP, UK

3 Great Ormond Street Hospital NHS Trust, London, UK

4 Immunodeficiency Centre for Wales, University Hospital of Wales, Cardiff, UK

5 Division of Infection \& Immunity, School of Medicine, Cardiff University, Cardiff, UK

6 Department of Pediatrics, Faculty of Medicine, Kuwait University, Kuwait City, Kuwait
7 Department of Clinical Immunology, Addenbrooke's Hospital, Cambridge, UK

Laboratorio de Inmunologia, UNAM, FES Cuautitlan, Cuautitlan, Mexico

9 University College London NHS Foundation's Trust/University College, London, UK

10 Children's Hospital Iceland, Landspitali - University Hospital, Reykjavík, Iceland

11 Division of Allergy and Immunology, The Children's Hospital of Philadelphia, Philadelphia, PA, USA

12 Center for Chronic Immunodeficiency, Medical Center, Faculty of Medicine, Albert-Ludwigs-University, Freiburg, Germany 


\section{Introduction}

Autosomal dominant hyper-IgE syndrome is a rare primary immunodeficiency (PID) with multisystem pathology [1], caused by dominant-negative loss-of-function (LOF) mutations in signal transducer and activator of transcription factor 3 (STAT3) [2, 3] (STAT3-HIES). STAT3 is integral to lymphocyte development and differentiation. STAT3-deficient humans and mice have impaired cellular and humoral immune responses [4, 5], explaining the diverse immunologic manifestations [2-4]. In the context of infection, there is poor differentiation of $T$ lymphocytes into $T_{H} 17$ cells, resulting in low IL17 and IL22 production [6], which contributes to susceptibility to encapsulated organisms and fungi.

HSCT was initially reported as unsuccessful in STAT3HIES by our group [7]. Based on this impression, supportive treatment has been largely adopted [1], but many patients develop severe life-limiting pulmonary disease. However, over the years, eight case reports of allogeneic hematopoietic stem cell transplant (HSCT) for STAT3-HIES have been published [7-12], three of them performed following the diagnosis of non-Hodgkin's B cell lymphoma, which is a known complication of this primary immunodeficiency [8]. In these eight cases, five patients had received myeloablative conditioning regimens, while three had reduced-intensity conditioning. Seven patients, including two with Hodgkin's lymphoma, were recently reported as alive and well 4-20 years following report of HSCT [13], while one patient had died from the preexisting lymphoma post-transplant [10].

We initially reported failure of HSCT to resolve or cure the immune defect in our first patient. However, we now acknowledge that STAT3-HIES patients have experienced sustained benefit from HSCT. At the time of our report, the molecular cause of STAT3-HIES was unknown, and we based our statements on failure to normalize the serum $\operatorname{IgE}$ level and an apparent failure to change the immunological defect. We have now shown that the IL17A levels of that patient approaches normal (although not measured pretransplant) and memory B-lymphocytes are present. We now report a series of eight patients successfully treated with HSCT in the UK, including the long-term follow up of our previously reported patient [7].

\section{Methods}

We conducted a retrospective review of medical records of STAT3-HIES patients from two UK transplant centers for PID. We included only patients with confirmed dominantnegative STAT3 mutations who have undergone allogeneic HSCT. We recorded pre-transplant co-morbidities, conditioning, outcome, and on-going co-morbidities in eight patients who received nine transplants.
In selected patients for whom samples were available, IL17A levels were measured by Luminex (Bio-Plex, Biorad, UK) [14], 24 hours after stimulation in whole blood (96 Costar-F plates, 1:5 diluted in RPMI) of healthy controls and patients. Stimulations were performed using PHA (SigmaAldrich, $10 \mu \mathrm{g} / \mathrm{ml}$ ) and compared with unstimulated medium samples. Data were compared with historic controls, which had been stimulated under identical conditions. $P$ values were calculated using the two-tailed Mann-Whitney test or the Wilcoxon matched pairs test, excluding the data of P5 before HSCT.

Parents, and, where appropriate, patients consented to the procedure and data collection.

\section{Results}

Transplants were performed between 1996 and 2019 . Demographic data, genetic mutation, and pre-HSCT clinical status are summarized in Table 1. All patients had dominant loss-of-function mutations in STAT3 with a classical clinical phenotype, and all had significant lung or skin-related complications prior to HSCT.

Details of conditioning regimen, cell source, and graftversus-host disease (GvHD) prophylaxis are detailed in Table 2. One patient received conventional myeloablative conditioning, four received reduced-toxicity myeloablative conditioning, and three received reduced intensity conditioning, one of whom rejected and was successfully retransplanted following a reduced-toxicity myeloablative regimen (patient six). All inoculi were matched at 10/10 HLAloci, apart from the first product for patient six, which was a 9/ 10 match (DQ mismatch).

All patients survived and no patient experienced significant GvHD. Seven patients had complete or high level (>90\%) donor chimerism and one had partial chimerism; however, all had improvement in immune phenotype, with a reduction in clinical symptoms, halting of progression of lung disease and improvement in skin infections. Non-immune manifestations showed variable improvement, with one patient developing further fractures and two patients demonstrating worsening scoliosis post-transplant. One patient has recently had vasculopathy with an ST segment elevation myocardial infarction with ectatic coronary vasculature [12]. Patient clinical status post-HSCT are summarized in Table 3.

In the one patient (patient 5) for whom pre- and posttransplant IL17A levels were available, IL17A was higher post-transplant. For patients 2, 3, and 4, IL17A levels were present post-transplant, but lower than controls (Fig. 1).

Patient 1 had significant pulmonary infection (complicated cystic bronchiectasis with Pseudomonas infection and widespread Aspergillus infection leading to pulmonary hypertension) with two lobectomies, complicated by development of 


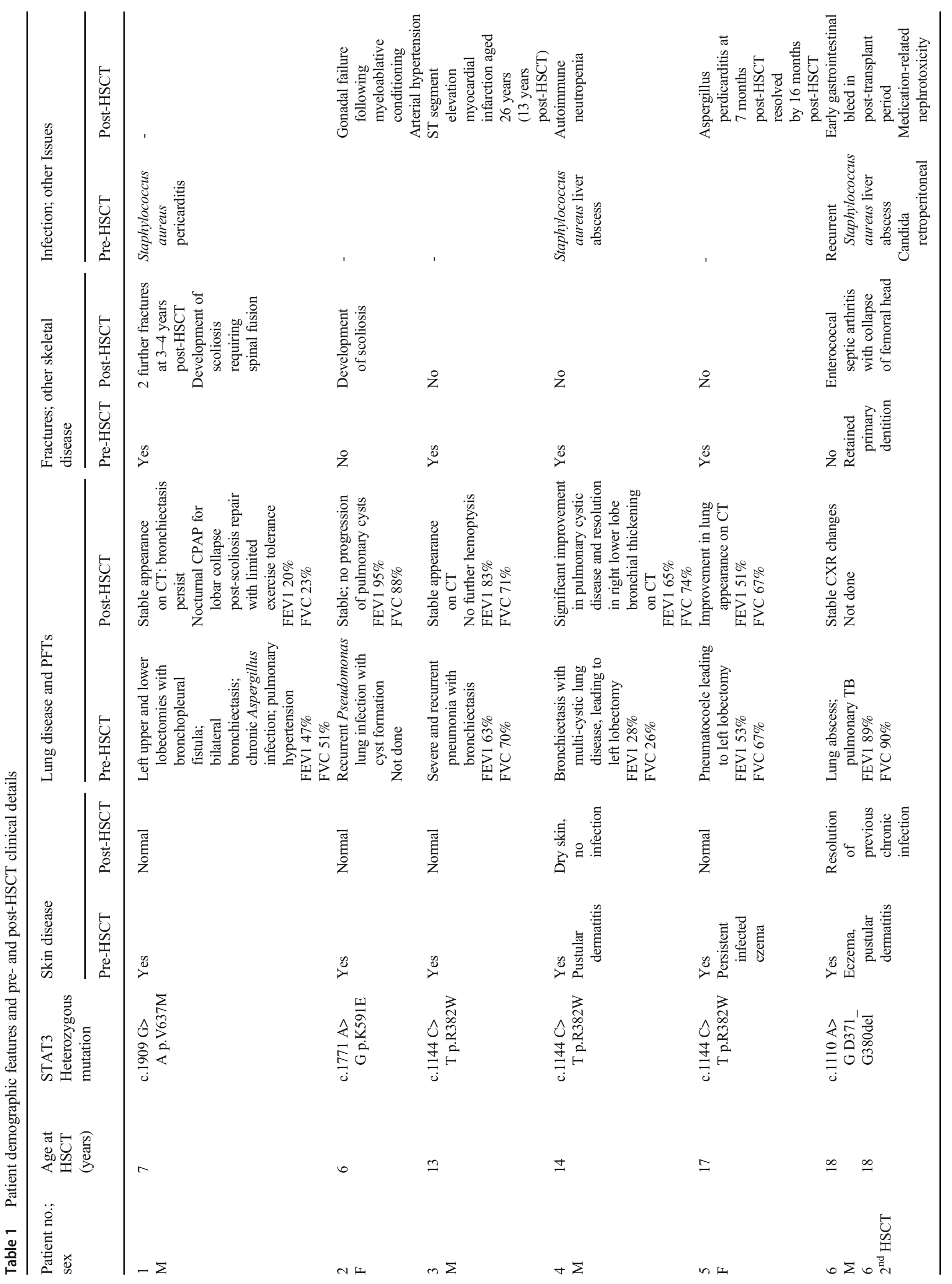




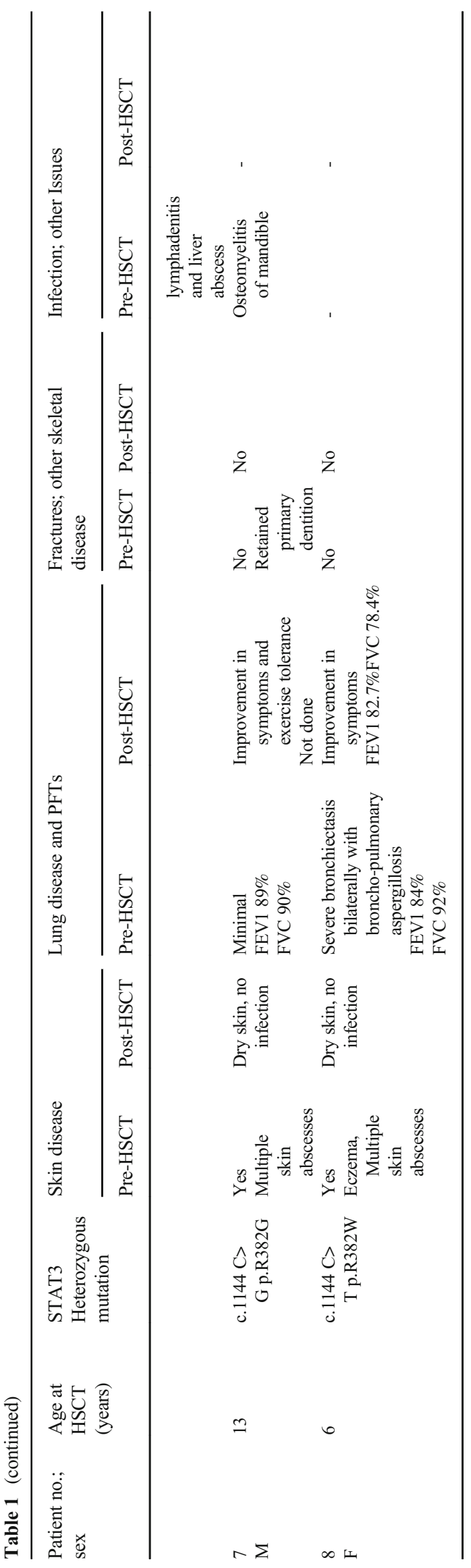

bronchopleural fistula. He subsequently developed a Staphylococcus aureus pericarditis requiring surgical drainage, complicated by prolonged air leak. Transplantation at age 7 years was relatively uncomplicated. There was no viral re-activation, progression of chest lesions, or acute graft versus host disease. Six years post-transplant, his eczema had resolved and he was no longer getting significant respiratory infections. Immunoglobulin support has ceased, and normal vaccine and T-lymphocyte proliferative responses have been demonstrated. His scoliosis, exacerbated by his two previous left sided lobectomies, had deteriorated requiring spinal fusion surgery. Following this, his right lower airway integrity has been compromised, severely impairing his respiratory capacity. He now is reliant on overnight CPAP and can only ambulate short distances.

Patient 2 experienced frequent staphylococcal skin infections and cystic bronchiectasis infected with Pseudomonas, because of which transplantation was offered when aged 6 years. Despite $100 \%$ donor chimerism, the procedure was initially described as unsuccessful [7] because of continued elevated serum IgE. However, long-term follow-up confirmed sustained clinical improvement with no further respiratory or skin infections. Serum IgE levels diminished and remained reduced, and immunoglobulin support is no longer required. She developed thoracolumbar scoliosis, arterial hypertension, and gonadal failure. With 20 years follow-up, pulmonary status includes stable lingular bronchiectasis and nonprogressive right upper lobe pulmonary cysts.

Patient 3 experienced frequent severe bronchopneumonias and progressive bronchiectasis despite immunoglobulin replacement, as well as osteopenia and lumbar vertebrae compression fractures. Transplantation at 13 years was relatively uneventful, and 13 years post-transplant, he demonstrates $100 \%$ donor chimerism with reduced serum IgE levels. Lung function has improved to normal values. Hemoptysis has stopped, and there is no computerized tomographic evidence of pulmonary disease progression. An increase in IL17A production after polyclonal stimulation was demonstrated post-HSCT (Fig. 2), and $\mathrm{T}_{\mathrm{H}} 17$ cells display normal response to IFN- $\gamma$ and IL12 and normal IL12 production (data not shown). However, at 11 years post-HSCT, he sustained an anterior myocardial infarction, accompanied by classical clinical, electrocardiographic and biochemical signs and parameters. Angiography revealed proximal ectasia causing midvessel occlusion of his left anterior descending coronary artery but otherwise unobstructed coronary vessels. He was commenced on aspirin $75 \mathrm{mg}$ for 3 months with rivaroxaban $2.5 \mathrm{mg}$ BID for 3 years and clopidogrel $75 \mathrm{mg}$ long term [12].

Patient 4 developed bronchiectasis, Staphylococcus aureus liver abscess, and recurrent skin abscesses. Severe multicystic and suppurative lung disease warranted left upper lobectomy. Following transplantation at age 14 years, repeat computerized tomography demonstrated significant 
Table 2 Patient transplant demographics

\begin{tabular}{|c|c|c|c|c|c|c|}
\hline Patient & Follow-up & Cell source; HLA Match & Conditioning regimen & GvHD prophylaxis & Acute GvHD & Latest donor chimerism \\
\hline 1 & 6 years & $\begin{array}{l}\text { URD PBSC } \\
10 / 10\end{array}$ & $\begin{array}{l}\text { Alemtuzumab } 1 \mathrm{mg} / \mathrm{kg} \\
\text { Fludarabine } 150 \mathrm{mg} / \mathrm{m}^{2} \\
\text { Melphalan } 140 \mathrm{mg} / \mathrm{m}^{2}\end{array}$ & $\begin{array}{l}\text { CSA } \\
\text { MMF }\end{array}$ & - & $\begin{array}{l}\text { CD15 55\% } \\
\text { CD19 55\% } \\
\text { CD3 } 86 \%\end{array}$ \\
\hline 2 & 20 years & $\begin{array}{l}\text { URD BM } \\
10 / 10\end{array}$ & $\begin{array}{l}\text { Alemtuzumab } 1 \mathrm{mg} / \mathrm{kg} \\
\text { busulphan } 16 \mathrm{mg} / \mathrm{kg} \\
\text { Cyclophosphamide } 200 \mathrm{mg} / \mathrm{kg}\end{array}$ & CSA & Grade 1 skin & WB $100 \%$ \\
\hline 3 & 11 years & $\begin{array}{l}\text { URD BM } \\
10 / 10\end{array}$ & $\begin{array}{l}\text { Alemtuzumab } 1 \mathrm{mg} / \mathrm{kg} \\
\text { Fludarabine } 150 \mathrm{mg} / \mathrm{m}^{2} \\
\text { Melphalan } 140 \mathrm{mg} / \mathrm{kg}\end{array}$ & $\begin{array}{l}\text { CSA } \\
\text { MMF }\end{array}$ & - & WB $100 \%$ \\
\hline 4 & 3 years & $\begin{array}{l}\text { MSD PBSC } \\
10 / 10\end{array}$ & $\begin{array}{l}\text { Alemtuzumab } 1 \mathrm{mg} / \mathrm{kg} \\
\text { Treosulfan } 42 \mathrm{~g} / \mathrm{m}^{2} \\
\text { Fludarabine } 150 \mathrm{mg} / \mathrm{m}^{2}\end{array}$ & $\begin{array}{l}\text { CSA } \\
\text { MMF }\end{array}$ & Grade 1 skin & $\begin{array}{l}\text { CD15 100\% } \\
\text { CD19 100\% } \\
\text { CD3 } 91 \%\end{array}$ \\
\hline 5 & 3 years & $\begin{array}{l}\text { URD PBSC } \\
10 / 10\end{array}$ & $\begin{array}{l}\text { Alemtuzumab } 1 \mathrm{mg} / \mathrm{kg} \\
\text { Fludarabine } 150 \mathrm{mg} / \mathrm{m}^{2} \\
\text { Treosulphan } 42 \mathrm{~g} / \mathrm{m}^{2}\end{array}$ & $\begin{array}{l}\text { CSA } \\
\text { MMF }\end{array}$ & Grade 1 skin & WB $100 \%$ \\
\hline 6 & - & $\begin{array}{l}\text { Mismatched URD PBSC } \\
9 / 10 \\
\text { (DQ mismatch) }\end{array}$ & $\begin{array}{l}\text { Alemtuzumab } 60 \mathrm{mg} \\
\text { Fludarabine } 150 \mathrm{mg} / \mathrm{m}^{2} \\
\text { Melphalan } 140 \mathrm{mg} / \mathrm{m}^{2}\end{array}$ & CSA & - & $\begin{array}{l}\text { Hyperacute rejection } \\
\text { D+13 }\end{array}$ \\
\hline & 2 years & $\begin{array}{l}\text { URD BM } \\
10 / 10\end{array}$ & $\begin{array}{l}\text { ATG Fludarabine } 150 \mathrm{mg} / \mathrm{m}^{2} \\
\text { Treosulphan } 42 \mathrm{~g} / \mathrm{m}^{2} \\
\text { Thiotepa } 10 \mathrm{mg} / \mathrm{kg}\end{array}$ & $\begin{array}{l}\text { CSA } \\
\text { MMF }\end{array}$ & - & WB $100 \%$ \\
\hline 7 & 20 months & $\begin{array}{l}\text { URD PBSC } \\
10 / 10\end{array}$ & $\begin{array}{l}\text { Alemtuzumab } 1 \mathrm{mg} / \mathrm{kg} \\
\text { Fludarabine } 150 \mathrm{mg} / \mathrm{m} 2 \\
\text { Treosulphan } 42 \mathrm{~g} / \mathrm{m} 2\end{array}$ & $\begin{array}{l}\text { CSA } \\
\text { MMF }\end{array}$ & - & WB $100 \%$ \\
\hline 8 & 15 months & $\begin{array}{l}\text { MSD BM } \\
10 / 10\end{array}$ & $\begin{array}{l}\text { Alemtuzumab } 1 \mathrm{mg} / \mathrm{kg} \\
\text { Fludarabine } 150 \mathrm{mg} / \mathrm{m}^{2} \\
\text { Treosulphan } 42 \mathrm{~g} / \mathrm{m}^{2}\end{array}$ & $\begin{array}{l}\text { CSA } \\
\text { MMF }\end{array}$ & - & $\begin{array}{l}\text { CD15 96\% } \\
\text { CD19 94\% } \\
\text { CD3 94\% }\end{array}$ \\
\hline
\end{tabular}

widespread decrease in the number and size of previously reported large cysts, and there was a clinical improvement in the eczematous skin lesions. Post-transplant IL17A production was normal.

Patient 5 developed multiple abscesses and pneumatoceles during infancy leading to right upper lobectomy and bronchopulmonary fistula at age 13 years. Pulmonary function was impaired prior to HSCT, aged 17 years. Non-invasive pulmonary Aspergillus infection persisted post-HSCT, treated with appropriate long-term anti-fungal therapy-at 7 months posttransplant, and Aspergillus pericarditis was diagnosed, which resolved with dual anti-fungal therapy by 16 months posttransplant. Thoracic computerized tomography demonstrated a dramatic improvement in lung appearance, and the residual right upper lobe cavity remained stable.

Patient 6 had persistent multiple skin infections with severe eczema and lymphadenitis through childhood and a single lung abscess. Additionally, a persistent Staphylococcus aureus hepatic abscess required surgical drainage on four occasions. Further to this, the patient required surgical excision of Candida albicans retroperitoneal lymphadenitis and a fungal liver abscess. The patient developed bowel perforation of unknown etiology at 6 years of age, before HSCT. An immune-mediated acute rejection of first graft was confirmed at day 13 post-transplant, followed by an autologous recovery. In this period, the patient experienced an enterococcal septic arthritis, with collapse of femoral head, gastrointestinal hemorrhage, and further episodes of fungal lymphadenitis. A second transplant procedure using a reduced toxicity treosulfanbased regimen was successful. The patient has good immune reconstitution and has ceased immunosuppression and immunoglobulin replacement.

Patient 7 was first referred to pediatric care at the age of 4 weeks due of eczema and skin infections, mainly on the face and scalp, from which Staphylococcus aureus was isolated and treated. Serum IgE levels were elevated prompting a diagnosis of Hyper IgE syndrome, confirmed genetically. The patient continued to have numerous recurrent skin abscesses, requiring drainage over 20 times per year despite antibiotic treatment and immunoglobulin replacement. He subsequently developed mandibular osteomyelitis. Pulmonary disease was limited to asthma only, with no significant infection. Transplant was uncomplicated, and at 20 months postHSCT, his skin is much improved with no new infections. $\mathrm{He}$ has discontinued immunoglobulin and is awaiting vaccination.

Patient 8 presented as a neonate with staphylococcal skin infection and went on to develop recurrent skin infection, pneumonia, and otitis media. She demonstrated elevated serum IgE with poor pneumococcal antibody titers following vaccination and almost no $\mathrm{T}_{\mathrm{H}} 17$ cells. Her pulmonary disease progressed with findings of Aspergillus on bronchoalveolar 


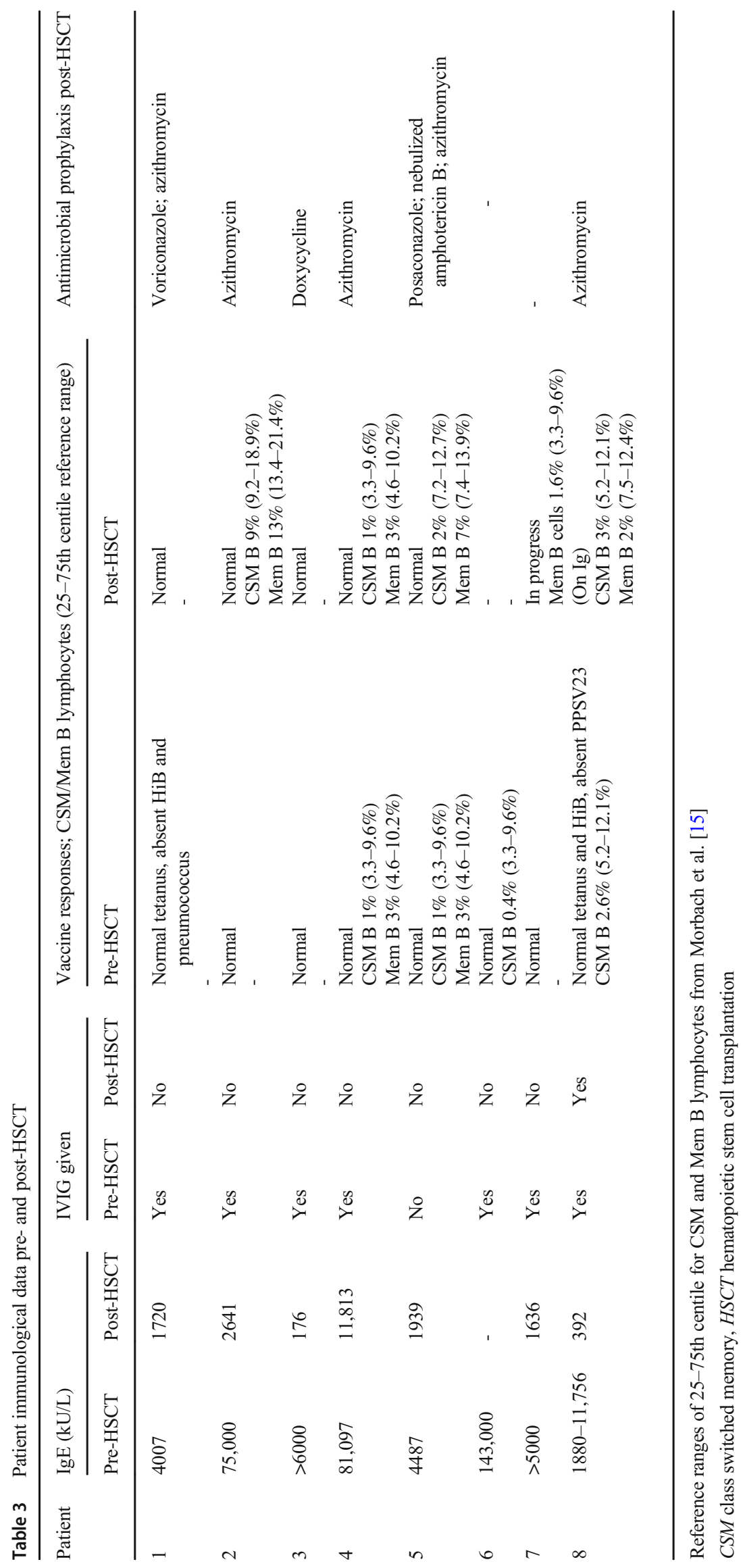




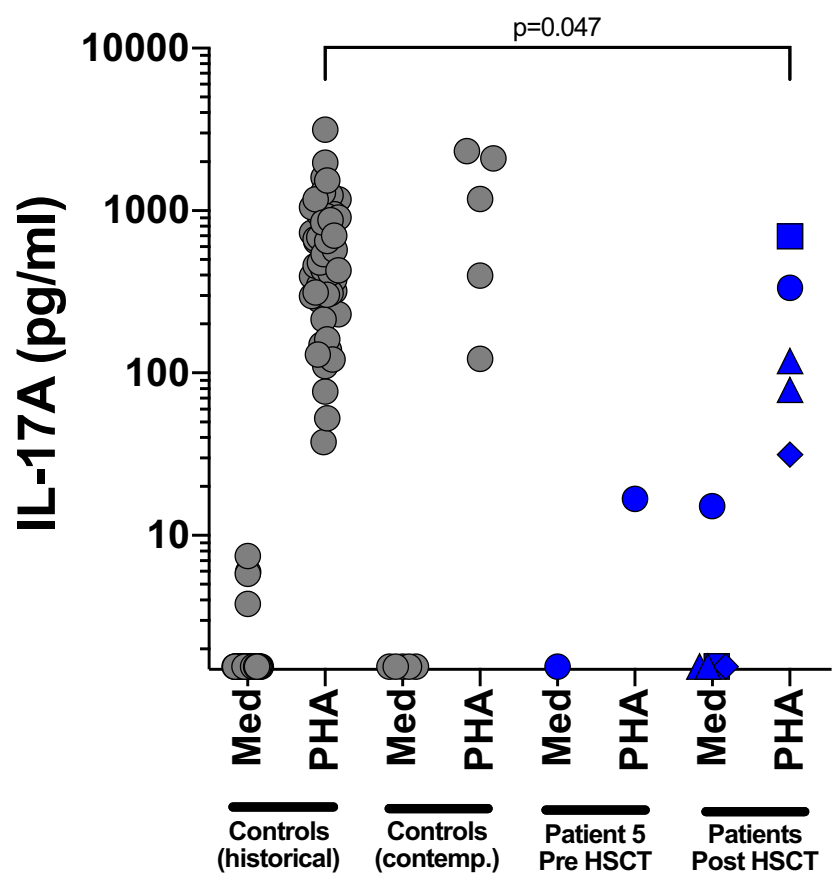

Fig. 1 IL17A levels in healthy controls and patients post-transplant. IL17A levels were measured by Luminex (Bio-Plex, Biorad, UK) 24 hours after stimulation in whole blood (96 Costar-F plates, 1:5 diluted in RPMI) of healthy controls (historical and contemporary) and patients (P2 - blue diamonds, P3 - blue triangles, P4 - blue squares, P5 (pre and post HSCT) - blue circles). Stimulations were done using PHA (SigmaAldrich, $10 \mu \mathrm{g} / \mathrm{ml}$ ) and compared with unstimulated medium samples (Med)

lavage leading to a diagnosis of allergic bronchopulmonary aspergillosis, treated with antifungal therapy, corticosteroids, and anti-IgE monoclonal antibodies. She underwent HSCT aged 6 years with an uncomplicated course. One year postHSCT, she reports only dry skin with no infection. Pulmonary function is stable and she is asymptomatic from cough or dyspnoea. Serum IgE has fallen to $392 \mathrm{kU} / \mathrm{L}$. She remains on immunoglobulin replacement but has normal B lymphocyte numbers.

\section{Discussion}

Published data on the outcome of allogeneic HSCT for STAT3-HIES patients are limited, perhaps stemming from our initial report indicating non-utility [7]. A recent report by Oikonomopoulou et al. [13] summarizes the data of 7 patients transplanted between 1998 and 2018, one of which was the patient we originally reported in 2000 [7]. For three of these, the transplant indication was lymphoma $[9,10]$, and thus, although the STAT3-HIES was reported as cured, their transplant indication and management could be considered separately. The first of these patients died 6 months following transplant from interstitial pulmonary fibrosis, although with pre-existing abnormal immune parameters, including raised
IgE, normalized post-transplant [10]. The other two patients, with follow up of 10 and 14 years, respectively, both with $100 \%$ donor chimerism, were reported to have normalized immunological parameters including a normalized proportion of $\mathrm{T}_{\mathrm{H}} 17^{+}$lymphocytes. Furthermore, other abnormalities associated with STAT3-HIES, including coarse facies and osteoporosis, were reported to have resolved, and there was no symptomatic development of STAT3-HIES-associated vasculopathy, although it is not clear if any screening was performed [9]. A further patient, transplanted because of a complicated infectious history, was reported after 42 months of follow-up. The patient had full donor chimerism and remained infection-free after discontinuing anti-microbial prophylaxis. Vaccine antibody responses were demonstrated and IgE normalized, STAT3 signaling was restored in hematopoieticderived cells, and the percentage of Th $17^{+}$lymphocytes and central memory $\mathrm{T}$ lymphocytes to normal ranges was established [11]. Finally, 2 patients, transplanted for recurrent infection, were reported with 8 and 10 years of follow-up, respectively. Immunological parameters normalized and the infection frequency significantly diminished, but nonimmunological features of STAT3-HIES remained, including a propensity to recurrent fractures and development of a new pneumatocele, associated with $\leq 50 \%$ donor chimerism [8].

Our current report extends follow-up of the initial patient to over 18 years and reports on a further 7 patients, one recently published in the context of new onset vasculopathy complications [12], thus contributing the largest series to date. Perhaps the most remarkable observation is that despite pre-transplant severe, progressive lung disease - itself a significant risk factor for HSCT outcome - as well as other significant pretransplant sequelae, all patients in our series survived. Importantly, pulmonary disease has stabilized in all and improved in some, as demonstrated on clinical, functional, and radiological parameters (Table 1; Fig. 3). No peri-transplant pulmonary inflammatory complications were observed, unlike the post-HSCT course seen in many PID patients. GvHD was infrequent and insignificant. Notably, no patients have required further lung surgery post-HSCT. Most patients have remained on some antimicrobial prophylaxis, in view of treating physician concerns of recurrent infections in preexisting bronchiectatic lungs - despite this, control of lung disease reported by patients has stabilized or improved. Aspergillus infection, likely from pre-existing colonization or infection, recurred through, or after transplantation in some, but did not cause the severe complications usually associated with transplant-associated aspergillosis. Other significant infections reduced in frequency or resolved completely, accepting that most patients remained on antimicrobial prophylaxis. Importantly, eczema improved in all patients and skin infections were abolished post-transplant.

STAT3 plays an important part in normal endothelial cell biology [16], and endothelial dysfunction is known to 

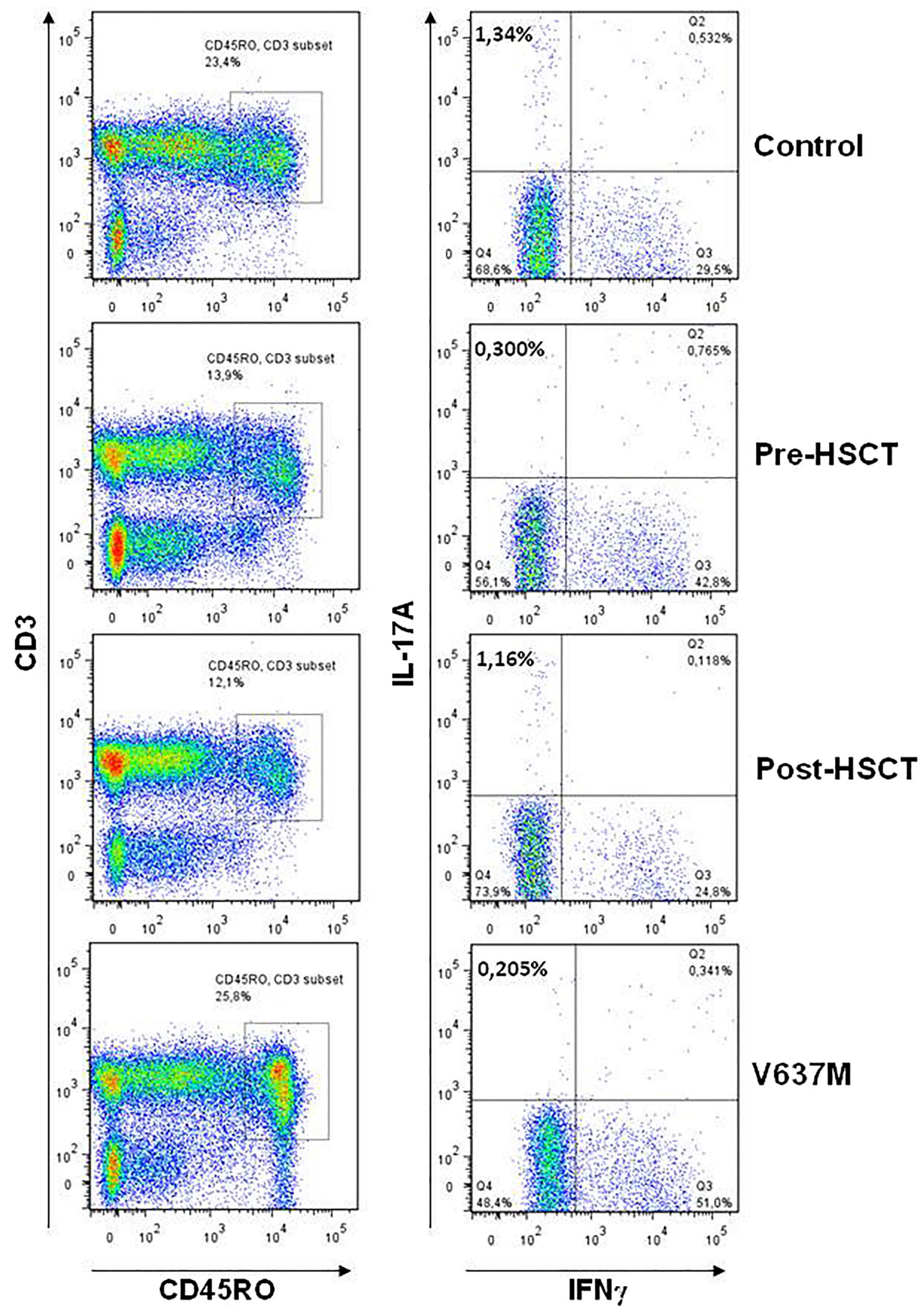

Fig. 2 Pre- and post-transplant peripheral blood mononuclear cells demonstrate that IL17A is absent pre-transplant and present post-transplant (patient 3 ), with normal control and a negative control patient who has not been transplanted (p.V637M) 

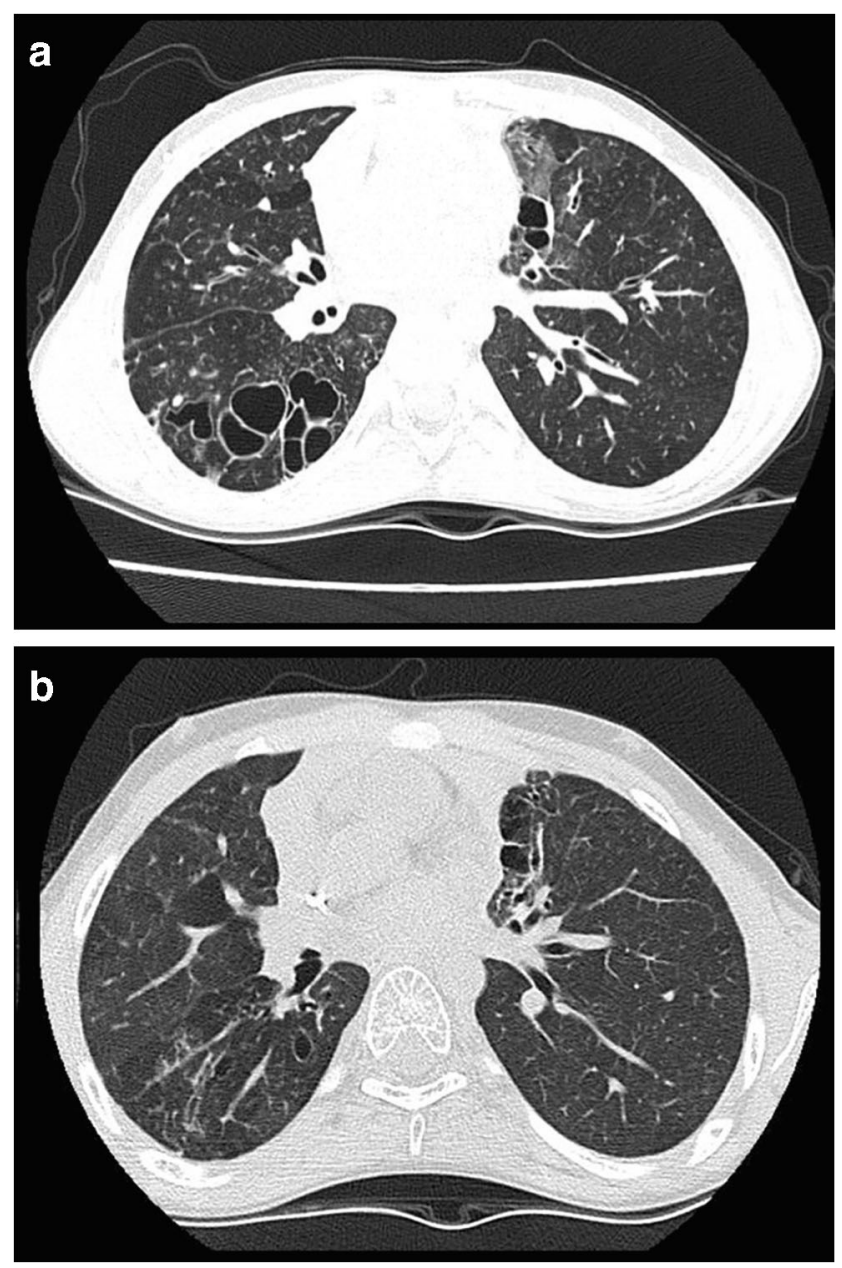

Fig. 3 Thoracic computerized tomography images from patient 4. a Images taken 1 year pre-transplant showing markedly abnormal lung parenchyma with large cysts, bullae, and cystic bronchiectasis particularly in the right lower lobe in association with cylindrical bronchiectasis, bronchial wall thickening, bronchocoeles, and reduced lung attenuation. b Images taken 1 year post-transplant showing several thin walled pulmonary "cysts," similar to previous pre-transplant findings and are therefore most likely to result from previous infection and lung destruction. Some regions of parenchymal distortion and scarring are also similar. There is some bronchial dilatation and distortion in regions of scarring, but no convincing evidence of bronchiectasis

contribute to initiation of transplant-related inflammatory complications [17]. It may be that the lack of severe postHSCT inflammatory complications including acute graftversus-host disease, observed in these patients and the previously reported cases, might be due to reduced endothelial cell upregulation, conferred by dominant negative STAT3-LOF mutations.

Although serum IgE levels remain above the adult reference range, they are substantially lower post-HSCT compared with pre-HSCT levels, although, in non-transplanted patients, IgE levels may fall over time [1]. More importantly, in those patients for whom data were available, normal $\mathrm{T}_{\mathrm{H}} 17$ function and associated cytokine responses are demonstrated (Fig. 1), confirming previous reports $[8,9,11]$.
As expected, many extra-immune manifestations have not resolved post-HSCT, and patients retain coarse facial features, as well as bone-related complications, although it is noteworthy that only one patient has developed fractures post-transplantation. No patient has developed lymphoma to date. Critically, however, one patient (\#3) recently experienced an anterior myocardial infarction, with evidence of thrombotic occlusion of dilated (ectatic) coronary vessels upon angiography. We estimated this patient's 10-year risk of developing a heart attack or stroke, using the QRISK3 calculator, as $0.1 \%$, which suggests that conventional cardiovascular risk factors were unlikely to account for the event, and disease-associated vasculopathy is more likely to be implicated [12]. Screening of coronary vasculature had not been performed prior to this event, and so it is unclear whether HSCT ameliorated, accelerated, or had no effect on these coronary vessels. Whether earlier HSCT will favorably alter the pre-disposition to vascular complications documented in these patients remains to be seen. Further research is required to establish the clinical significance of these wider complications of STAT3-HIES and capture the long-term impact of STAT3-HIES on patients' quality of life across the spectrum of presentations.

Contrary to our previous assertion [7], this series, along with other published reports, further supports the notion that allogeneic HSCT can improve the immunological deficit, modify the pulmonary course in these patients, and improve the skin condition. The future challenge will be to identify which patients will benefit from early consideration of this therapy to prevent endorgan damage, reduce hospitalization and improve quality of life, as well as which conditioning regimen to use. The importance of complete or high donor chimerism is not established, and further work is required to determine optimum conditioning regimens and minimum effective donor chimerism level. Furthermore, it will be particularly important to determine whether HSCT can alter the risk of developing vascular anomalies, which may be associated with significant morbidity and mortality.

Author Contribution ARG conceived the study. SCH, MAS, ARG, and CT collated and analyzed the data and wrote the manuscript; ZN, AW, PV, MJP, JM, AC, SJ, WAH, TJF, AJC, and MA provided clinical data; BG provided genetic analysis and flow cytometry data; RD and GB-M provided cytokine data; all authors contributed to writing of the manuscript and approved the final version.

Funding CT is supported by The Job Research Foundation.

MJP is supported by the Welsh Clinical Academic Training (WCAT) programme and is a participant in the NIH Graduate Partnership Program.

BG receives support through the Deutsche Forschungsgemeinschaft (DFG) SFB1160/2_B5, under Germany's Excellence Strategy (CIBSSEXC-2189-Project ID 390939984, and RESIST-EXC 2155-Project ID 390874280); through the E-rare program of the EU, managed by the DFG, grant code GR1617/14-1/iPAD, and through the "Netzwerke Seltener Erkrankungen" of the German Ministry of Education and Research (BMBF), grant code: GAIN_01GM1910A. This work was supported in part by the Center for Chronic Immunodeficiency (CCI), Freiburg Center for Rare Diseases (FZSE). 
Data availability For further information please contact ARG: a.r.gennery@ncl.ac.uk.

\section{Compliance with ethical standards}

Ethics Approval and Consent to Participate Not applicable

Consent for Publication Not applicable

Competing Interests The authors declare that they have no competing interests.

Open Access This article is licensed under a Creative Commons Attribution 4.0 International License, which permits use, sharing, adaptation, distribution and reproduction in any medium or format, as long as you give appropriate credit to the original author(s) and the source, provide a link to the Creative Commons licence, and indicate if changes were made. The images or other third party material in this article are included in the article's Creative Commons licence, unless indicated otherwise in a credit line to the material. If material is not included in the article's Creative Commons licence and your intended use is not permitted by statutory regulation or exceeds the permitted use, you will need to obtain permission directly from the copyright holder. To view a copy of this licence, visit http://creativecommons.org/licenses/by/4.0/.

\section{References}

1. Grimbacher B, Holland SM, Gallin JI, Greenberg F, Hill SC, Malech HL, et al. Hyper-IgE syndrome with recurrent infectionsan autosomal dominant multisystem disorder. N Engl J Med. 1999;340:692-702.

2. Holland SM, DeLeo FR, Elloumi HZ, et al. STAT3 mutations in the Hyper-IgE-syndrome. N Engl J Med. 2007;357:1608-19.

3. Minegishi Y, Saito M, Tsuchiya S, Tsuge I, Takada H, Hara T, et al. Dominant negative mutations in the DNA-binding domain of STAT3 cause hyper-IgE syndrome. Nature. 2007;448:1058-62.

4. Kane A, Deenick EK, Ma CS, Cook MC, Uzel G, Tangye SG. STAT 3 is a central regulator of lymphocyte differentiation and function. Curr Opin Immunol. 2014;28:49-57.

5. Steward-Tharp SM, Laurence A, Kanno Y, Kotlyar A, Villarino AV, Sciume G, et al. A mouse model of HIES reveals pro and anti-inflammatory functions of STAT 3. Blood. 2014;123:297887.

6. de Beaucoudrey L, Puel A, Filipe-Santos O, Cobat A, Ghandil P, Chrabieh M, et al. Mutations in STAT3 and IL12RB1 impair the development of human IL-17-producing T cells. J Exp Med. 2008;205:1543-50.

7. Gennery AR, Flood TJ, Abinun M, Cant AJ. 2000. Bone marrow transplantation does not correct the hyper IgE syndrome. Bone Marrow Transplant. 2000;25:1303-5.

8. Yanagimachi M, Ohya T, Yokosuka T, Kajiwara R, Tanaka F, Goto $\mathrm{H}$, et al. The potential and limits of hematopoietic stem cell transplantation for the treatment of autosomal dominant Hyper-IgE syndrome. J Clin Immunol. 2016;36:511-6.

9. Goussetis E, Peristeri I, Kitra V, Traeger-Synodinos J, Theodosaki M, Psarra K, et al. Successful long-term immunologic reconstitution by allogeneic hematopoietic stem cell transplantation cures patients with autosomal dominant hyper-IgE syndrome. J Allergy Clin Immunol. 2010;126:392-4.

10. Nester TA, Wagnon AH, Reilly WF, Spitzer G, Kjeldsberg CR, Hill HR. Effects of allogeneic peripheral stem cell transplantation in a patient with Job syndrome of hyperimmunoglobulinaemia $\mathrm{E}$ and recurrent infections. Am J Med. 1998;105:162-4.

11. Patel NC, Gallagher JL, Torgerson TR, Gilman AL. Successful haploidentical donor hematopoietic stem cell transplant and restoration of STAT3 function in an adolescent with autosomal dominant hyper-IgE syndrome. J Clin Immunol. 2015;35:479-85.

12. Ponsford MJ, Clark J, Mock J, Abinun M, Carne E, El-Shanawany $\mathrm{T}$, et al. Hematopoietic stem cell transplantation and vasculopathy associated with STAT3-dominant-negative hyper-IgE syndrome. Front Pediatr. 2020;8(September):1-8.

13. Oikonomopoulou C, Goussetis E. Autosomal dominant hyper-IgE syndrome: when hematopoietic stem cell transplantation should be considered? Pediatr Transplant. 2020;24:e13699.

14. von Stemann JH, Rigas AS, Thorner LW, et al. Prevalence and correlation of cytokine-specific autoantibodies with epidemiological factors and C-reactive protein in 8,972 healthy individuals: results from the Danish Blood Donor Study. PLoS One. 2017;12: e0179981.

15. Morbach H, Eichhorn EM, Liese JG, Girschick HJ. Reference values for B cell subpopulations from infancy to adulthood. Clin Exp Immunol. 2010;162:271-9.

16. Jodele S, Laskin BL, Dandoy CE, Myers KC, el-Bietar J, Davies $\mathrm{SM}$, et al. A new paradigm: diagnosis and management of HSCTassociated thrombotic microangiopathy as multi-system endothelial injury. Blood Rev. 2015;29(3):191-204.

17. Hox V, O'Connell MP, Lyons JJ, et al. Diminution of signal transducer and activator of transcription 3 signaling inhibits vascular permeability and anaphylaxis. J Allergy Clin Immunol. 2016;138: 187-99.

Publisher's Note Springer Nature remains neutral with regard to jurisdictional claims in published maps and institutional affiliations. 